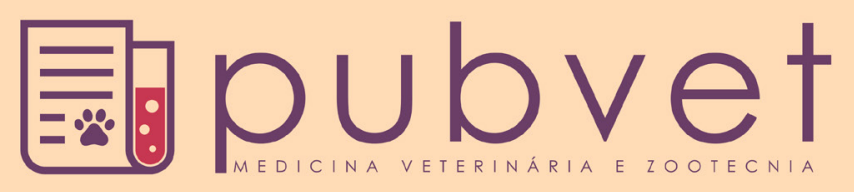

ISSN $1982-1263$

HTTP://DX.DOI.ORG/10.22256/PUBVET,V11N6.566-574

\title{
Caracterização do processamento artesanal da carne de caranguejo-uçá Ucides cordatus e perfil socioeconômico dos quebradores
}

\author{
Rutinéia de Souza Silva ${ }^{1}$, Werlanne Mendes ${ }^{2}$, Monica Giacometti Mai ${ }^{3}$, Fabíola Helena \\ dos Santos Fogaça ${ }^{*}$, Alitiene Moura Lemos Pereira ${ }^{5}$, João Avelar Magalhães ${ }^{6}$, Newton de \\ Lucena Costa ${ }^{7}$
}

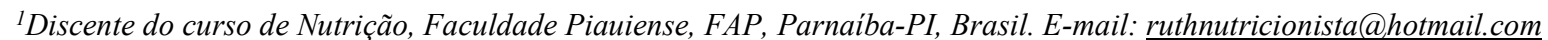

${ }^{2}$ Docente do curso de Nutrição, Faculdade Piauiense, FAP, Parnaiba-PI, Brasil.E-mail: werlannemendes@gmail.com

${ }^{3}$ Pesquisadora da Embrapa Agrossilvipastoril,.Sinop-MT,Brasil.E-mail:monica mai@hotmail.com

${ }^{4}$ Pesquisadora da Embrapa Meio-Norte, Parnaiba-PI, Brasil.E-mail: fabiola.fogaca@embrapa.br

${ }^{5}$ Pesquisadora da Embrapa Meio-Norte, Parnaiba-PI, Brasil.E-mail: alitiene.pereira@embrapa.br

${ }^{6}$ Pesquisadorda Embrapa Meio-Norte,Parnaiba-PI, Brasil.E-mail: joao.magalhaes@embrapa.br

${ }^{7}$ Pesquisador da Embrapa Roraima, Boa Vista-RR, Brasil.E-mail: newtonlucena@yahoo.com.br

*Autor correspondente, E mail: fabiola.fogaca@embrapa.br

RESUMO. O caranguejo-uçá Ucides cordatus é um dos crustáceos com maior importância econômica no Brasil, sendo fonte de renda e trabalho às comunidades que vivem de sua pesca. Seu consumo é um dos atrativos da culinária do Nordeste do país, proporcionando sustentação a bares e restaurantes temáticos bastante apreciados pelos turistas. Os caranguejos não vendidos pelos pescadores ou pelos comerciantes são processados artesanalmente para extração da carne ou massa de caranguejo. Este trabalho teve como propósito diagnosticar a situação socioeconômica dos trabalhadores envolvidos nesta atividade, bem como as condições higiênico-sanitárias de processamento, manipulação e acondicionamento da carne de caranguejo em locais chamados de "quebradeiras", verificando-se os parâmetros microbiológicos do produto. Foram avaliados oito locais de beneficiamento de carne de caranguejo, por meio de observações visuais, registros fotográficos, aplicação de questionário e entrevista semiestruturada. Amostras de carne de cada local foram coletadas para análise microbiológica (Coliformes termo tolerantes, Salmonella sp., estafilococo). Os resultados demonstraram um padrão semelhante de infraestrutura e práticas para o beneficiamento da carne nos diferentes locais. Foi constatado baixo nível de escolaridade dos quebradores, baixa renda familiar e pouco conhecimento sobre contaminação e boas práticas na manipulação de alimentos. Ainda assim, os resultados microbiológicos das amostras de carne de caranguejo demonstraram um padrão sanitário satisfatório.

Palavras chave: Alimento seguro, manipulação de alimentos, qualidade da carne

\section{Ucides cordatus meat crab artisanal processing characterization and breakers socioeconomic profile}

ABSTRACT. The Ucides cordatus mangrove crab is one of the most economically important crustaceans in Brazil, being a source of income and work for the fishing communities. Its consumption is one of the Northeastern cuisine attractions, supporting the thematic restaurants greatly appreciated by tourists. Crabs not sold by fishermen or traders are processed locally for meat or pasta crab extraction. This work aimed to diagnose the socioeconomic situation of the workers involved in this activity, as well as the hygienicsanitary conditions of processing, handling and packaging of crabmeat in places called 
"breakers", setting microbiological parameters for their meat. Eight local crabmeatprocessing sites were evaluated through visual observations, photographic records, questionnaire application and semi-structured interviews. Meat samples from each site were collected for microbiological analysis (thermos tolerant coliforms, Salmonella sp., Staphylococcus). The results showed a similar infrastructure and practices for meat processing in different locations. It was observed a low education level of breakers, low family income and poor knowledge about contamination and good practices in food handling. However, microbiology of crabmeat samples showed a satisfactory sanitary standard.

Keywords: Food handling, food safety, meat quality

\title{
Caracterización del procesamiento artesanal de la carne de cangrejo- uçá Ucides cordatus y perfil socioeconómico de los quebradores
}

\begin{abstract}
RESUMEN. El "caranguejo-uçá Ucides cordatus" es uno de los crustáceos con mayor importancia económica en Brasil, siendo una fuente de ingresos y trabajo a las comunidades que viven de su pesca. Su consumo es uno de los atractivos de la cocina del Nordeste del país, proporcionando sustento a bares y restaurantes temáticos muy apreciados por los turistas. Los cangrejos no vendidos por los pescadores o por los comerciantes son transformados artesanalmente para extracción de la carne o masa de cangrejo. Este trabajo ha tenido como propósito diagnosticar la situación socioeconómica de los trabajadores involucrados en esta actividad, bien como las condiciones higiénico-sanitarias de la transformación, manipulación y acondicionamiento de la carne de cangrejo en locales llamados de "quebradeiras", verificándose los parámetros microbiológicos del producto. Fueron evaluados ocho locales de transformación de carne de cangrejo, mediante observaciones visuales, registros fotográficos, aplicación de cuestionario e entrevista semiestructurada. Muestras de carne de cada local fueron recogidas para análisis microbiológica (Coliformes termo tolerantes, Salmonella sp., estafilococos). Los resultados demostraron un patrón semejante de infraestructura y prácticas para la transformación de la carne en los diferentes locales. Fue constatado un bajo nivel de escolaridad de los trabajadores ("quebradores"), bajos ingresos familiares y poco conocimiento acerca de la contaminación y buenas prácticas en la manipulación de alimentos. Sin embargo, los resultados microbiológicos de las muestras de carne de cangrejo demostraron uno patrón sanitario satisfactorio.
\end{abstract}

Palabras clave: Alimento seguro, manipulación de alimentos, calidad de la carne

\section{Introdução}

O caranguejo-uçá (Ucides cordatus) é o crustáceo com maior importância econômica nas regiões Norte e Nordeste do Brasil por ser fonte de subsistência e renda para as populações litorâneas (Sousa et al., 2015, Saint-Paul and Schneider, 2016). No Piauí, semanalmente são coletados e comercializados 48 mil caranguejos, oriundos do Delta do Parnaíba (Comissão Ilha Ativa, 2015).

Os caranguejos são comercializados em mercados e restaurantes, sendo parte processada artesanalmente, o que pode causar contaminação da carne extraída por microrganismos presentes naturalmente no produto, nos utensílios e manipuladores (Ristori et al., 2007). A falta de higiene durante o beneficiamento dos alimentos é fator determinante na incidência das Doenças Transmitidas por Alimentos - DTA's (Ogawa et al., 2008). Segundo dados do Ministério da Saúde, em 2013 foram registrados aproximadamente 20.000 casos de DTA's no Brasil (Agência Nacional Reguladora, 2014).

As DTA's constituem um problema de saúde pública mundial e estão frequentemente associadas a falhas na manipulação dos alimentos. Assim, o perfil socioeconômico e o nível de conhecimento do manipulador de alimentos podem influenciar a qualidade do produto final. Conhecer esses aspectos é essencial para programas de capacitação visando à segurança e qualidade dos alimentos (Devides et al., 2014).

O pescado, em geral, é mais perecível quando 
comparado a outras fontes proteicas (porco, frango e bovinos), necessitando de maiores cuidados na manipulação e armazenamento. No caso dos caranguejos, deterioram-se rapidamente, mesmo quando conservados em temperaturas de refrigeração $\left(\begin{array}{llll}0 & \text { a } & 4 & { }^{\circ} \mathrm{C}\end{array}\right)$, devido à elevada porcentagem de umidade e frágil estrutura das fibras de colágeno de sua carne, fatores favoráveis ao crescimento e degradação bacteriana ( et al., 2010).

No Brasil, a Agência Nacional de Vigilância Sanitária (ANVISA, 2001) estabelece "Limites Máximos Toleráveis" (LMT) de $5 \times 10^{2} \mathrm{UFC} / \mathrm{g}$ para Staphylococcus; ausência de Salmonella em $25 \mathrm{~g}$ de amostra e contagem abaixo de $10^{2} \mathrm{UFC} / \mathrm{g}$ para coliformes a $45^{\circ} \mathrm{C}$ para crustáceos in natura, resfriados ou congelados não consumidos crus. Esses microrganismos indicam em quais condições de higiene o pescado foi beneficiado, embalado e estocado (Calvet et al., 2010).

A cidade de Parnaíba, por ser rota obrigatória no trajeto de comercialização do caranguejo, concentra um número significativo de pontos de beneficiamento e venda desse crustáceo. No entanto, não há controle higiênico-sanitário nessas instalações e, portanto, não se conhecem as condições microbiológicas do produto nem os riscos ao consumidor.

Assim, o presente estudo teve como objetivo diagnosticar as condições e práticas de beneficiamento, acondicionamento e comercialização da carne de caranguejo processada artesanalmente em Parnaíba, Piauí, relacionando-as com sua qualidade microbiológica e com o perfil socioeconômico do quebrador. Espera-se que a pesquisa gere subsídios científicos que embasem a formulação de políticas públicas de boas práticas na manipulação do caranguejo-uçá, preservando-se o seu beneficiamento tradicional local.

\section{Material e Métodos}

\section{Área de estudo}

$\mathrm{O}$ estudo foi realizado no município de Parnaíba (254'185"; 4146'37"), situado no extremo Norte do Piauí, com uma população estimada de 149.803 habitantes. No aspecto social apresenta IDH de 0,687 e economia baseada no comércio de pescado e produtos agroalimentares e nos serviços públicos. Possui vegetação de igarapés e mangues, caatinga litorânea e mata de cocais, temperatura média de 27 a $29{ }^{\circ} \mathrm{C}$ e pluviosidade média de 1000 a $1600 \mathrm{~mm}$ (Instituto Brasileiro de Geografia e Estatística, 2015).

\section{Local da pesquisa}

A pesquisa foi realizada no ano de 2011, na zona urbana da cidade de Parnaíba, envolvendo os Bairros: Nova Parnaíba, Do Carmo, Nossa Senhora de Fátima e Centro. Tais locais foram escolhidos por possuírem maior fluxo comercial, seja pela produção ou comercialização da carne de caranguejo. A maioria dos quebradores constituise em residência própria, de alvenaria, porém a extração é realizada em área externa às residências, quintais ou alpendres e ainda estruturas de madeira com cobertura em plástico preto. Para diagnóstico do beneficiamento da carne de caranguejo foram escolhidos oito locais de extração artesanal, quatro quebradores de caranguejo, que realizam a atividade em forma de trabalho familiar, e mais quatro restaurantes, que serão identificados no trabalho como A, B, C, D, $\mathrm{E}, \mathrm{F}, \mathrm{G}$ e $\mathrm{H}$ a fim de preservar a identidade dos comerciantes locais.

\section{Coleta e análise dos dados}

Para a coleta dos dados foram realizadas entrevistas não estruturadas que proporcionam maior abrangência na condução de perguntas (Andrade et al., 2010), com auxílio de um questionário semiestruturado (Lakatos and Marconi, 2010), contendo perguntas sobre as condições de manipulação da carne de caranguejo comercializada no município de Parnaíba, considerando todos seus aspectos: características socioeconômicas, conhecimento sobre contaminação de alimentos, DTA's e boas práticas de manipulação, capacitação do manipulador de alimentos, situação e condições da edificação, equipamentos e utensílios, pessoal na área de produção/manipulação/venda, matéria prima, fluxo de produção/manipulação/venda e controle de qualidade. Também foi realizada observação não participante in loco, onde o pesquisador incorpora-se ao grupo estudado, participando das atividades de rotina, como forma de oferecer uma melhor percepção sobre o objeto estudado.

A pesquisa foi apresentada formalmente para cada quebrador/comerciante de caranguejo antes de cada entrevista, com leitura do Termo de Consentimento Livre Esclarecido (TCLE), para sanarem-se possíveis dúvidas sobre o trabalho, e após a anuência por parte dos entrevistados, o termo era assinado. Foi realizada uma análise estatística quantitativa dos dados. 
Análises microbiológicas da carne de caranguejo

Para avaliar a qualidade microbiológica da carne em relação às condições e práticas de beneficiamento do caranguejo, amostras congeladas $(500 \mathrm{~g})$ de cada local avaliado foram embaladas em caixas isotérmicas e enviadas ao Laboratório Saúde São Paulo, em Fortaleza, CE, creditado pelo Ministério da Agricultura, Pecuária e Abastecimento (MAPA) para laudos de amostras. Foram realizadas análises para a verificação da presença de Salmonella sp., estafilococos coagulase positiva e contagem de coliformes a $45^{\circ} \mathrm{C}$. Os critérios microbiológicos exigidos pela legislação brasileira para produtos à base de pescado, cozidos, em uma amostra indicativa, foram: ausência de Salmonella sp. em $25 \mathrm{~g}$ do alimento; coliformes a $45^{\circ} \mathrm{C}$ em níveis de até $5 \times 10 \mathrm{~g}^{-1}$; estafilococos coagulase positiva em níveis de até $10^{3} \mathrm{~g}^{-1}$ (ANVISA, 2001).

\section{Resultados e Discussão}

\section{Aspectos socioeconômicos}

A idade média dos quebradores entrevistados foi de 45 anos, variando de 37 a 62 anos. Verificou-se uma maior participação de quebradores na faixa de 30 a 49 anos (75\%) (Figura 1). Semelhante faixa etária foi observada na Comunidade de Caratateua, Pará, onde 53\% dos quebradores têm entre 31 e 50 anos e apenas $4 \%$ possuem idade acima de 50 anos (Brabo, 2009).

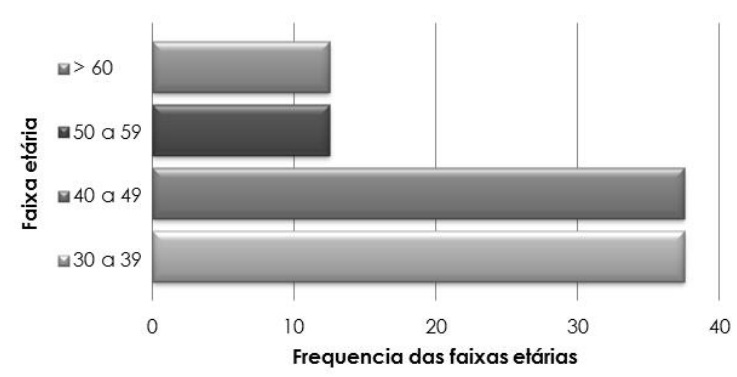

Figura 1. Distribuição segundo frequência das faixas etárias dos quebradores de carne de caranguejo em Parnaíba, PI.

Em comunidades pesqueiras, a quebra ou beneficiamento do caranguejo é uma atividade realizada em sua maioria por mulheres (Brabo, 2009). No entanto, em Parnaíba foi observada divisão igualitária (50\%) entre homens e mulheres, na gerência do negócio. Os homens realizam a compra do caranguejo, fazem o cozimento e a venda da carne. As mulheres $(81 \%)$, constituída principalmente por filhas e esposas por se tratar de uma atividade familiar, realizam a extração propriamente dita da massa do caranguejo.

Por ser um empreendimento familiar, $75 \%$ utiliza a própria residência para atividade e apenas $25 \%$ possuem um restaurante onde quebram o caranguejo. A média de pessoas que trabalha em cada ponto de beneficiamento é de 4,62 pessoas, sendo que $37,5 \%$ dos empreendimentos possuem até três ajudantes, $50 \%$ de 4 a 6 ajudantes e $12,5 \%$ acima de seis ajudantes (Tabela 1 ). O número de ajudantes é um fator preponderante na produção total de carne de caranguejo. Em comunidades tradicionais, $80 \%$ dos locais de beneficiamento trabalham com até três pessoas, produzindo em média 11 a $15 \mathrm{~kg}$ de carne/mês (Brabo, 2009). Em Parnaíba, a média de produção é de $67,5 \mathrm{~kg}$ para empreendimentos com 4 a 6 pessoas

Tabela 1. Características socioeconômicas dos quebradores de caranguejo em Parnaíba, PI.

\begin{tabular}{llc}
\hline Parâmetros & & $\%$ \\
\hline \multirow{2}{*}{ Gerência } & Homens & 50,0 \\
& Mulheres & 50,0 \\
\hline \multirow{2}{*}{ Ajudantes } & Familiares & 81,1 \\
& Contratados & 18,9 \\
\hline \multirow{2}{*}{ Número de ajudantes } & Até 3 pessoas & 37,5 \\
& De 4 a 6 pessoas & 50,0 \\
& $>6$ pessoas & 12,5 \\
Local de & Residência & 75,0 \\
beneficiamento & Restaurante & 25,0 \\
\hline \multirow{2}{*}{ Produção média, } & Até 3 pessoas & 35,0 \\
kg/mês & De 4 a 6 pessoas & 67,5 \\
& $>6$ pessoas & 100,0 \\
\hline \multirow{2}{*}{ Tempo na atividade, } & De 10 a 19 & 37,5 \\
anos & De 20 a 29 & 12,5 \\
& De 30 a 39 & 37,5 \\
& Acima de 40 & 12,5 \\
\hline
\end{tabular}

A escolaridade variou de não alfabetizado $(12,5 \%)$ a ensino médio incompleto $(25,0 \%)$. A maioria $(50,0 \%)$ possui ensino fundamental incompleto (até o quarto ano) (Tabela 2). O baixo grau de escolaridade das comunidades pesqueiras brasileiras é inerente a diversas localidades. $\mathrm{Na}$ comunidade de marisqueiras em Barra Grande, Cajueiro da Praia, Piauí, 17,46\% das pescadoras não são alfabetizadas e apenas $17,5 \%$ possuem o ensino fundamental incompleto (Freitas et al., 2012). Em comunidades da Paraíba, o analfabetismo chega a quase $27,0 \%$ (Nishida et al., 2008). O baixo nível de escolaridade justifica-se em razão da própria atividade pesqueira que exercem, pois a mesma ocupa boa parte do tempo 
e causa imenso cansaço físico aos pescadores, deixando-os desmotivados ao estudo (Borcem et al., 2012).

Tabela 2. Grau de escolaridade dos quebradores de carne de caranguejo em Parnaíba, PI.

\begin{tabular}{lc}
\hline Grau de escolaridade & Porcentagem (\%) \\
\hline Não alfabetizado & 12,5 \\
Fundamental incompleto & 50,0 \\
Fundamental completo & 12,5 \\
Médio incompleto & 25,0 \\
\hline
\end{tabular}

A renda familiar média obtida com a atividade de quebra e venda da carne de caranguejo varia em torno de $\mathrm{R} \$ 875,00$ (aproximadamente um salário) a R\$ 2.500,00 (aproximadamente três salários) (Tabela 3). Porém, 12,5\% dos quebradores não sabem estimar sua renda, o que demonstra falta de ferramentas de gestão da atividade. A renda é para o sustento da família e por isso não há investimento em infraestrutura para melhorias das condições de trabalho.

A renda é composta $100 \%$ pela receita bruta com a venda da carne de caranguejo (R\$ $25,00 / \mathrm{kg}$ ). Contabilizando-se o custo do caranguejo (R $\$ 0,80 /$ corda ou $\mathrm{R} \$$ 0,20 /caranguejo), o peso médio do caranguejo a $188 \mathrm{~g}$ (Galvão et al., 2010) e o rendimento de 21\% (Ogawa et al., 2008) para o caranguejo cozido, seriam necessários 26 caranguejos para obtenção de $1,0 \mathrm{~kg}$ de carne. $\mathrm{O}$ custo somente da matériaprima seria de $\mathrm{R} \$ 5,20 / \mathrm{kg}$ de carne. A Tabela 3 demonstra uma estimativa de receitas com a venda da carne de caranguejo segundo as produções observadas.

A renda mínima preconizada pela Organização das Nações Unidas (ONU) é de R\$ 8,08/dia/pessoa (US\$ 2,00) (Banco Mundial, 2008), sendo que os quebradores apresentaram renda familiar variando de $\mathrm{R} \$ 6,72 / \mathrm{dia} /$ pessoa para estabelecimentos de 3 a 4 pessoas a $\mathrm{R} \$$ 9,33/dia/pessoa para aqueles que trabalham com mais de seis ajudantes. Observou-se que as famílias com produção de até $35,0 \mathrm{~kg} / \mathrm{mês}$ (Tabela 1) não atingiram a renda mínima.

Todos os locais (residências e restaurantes) apresentaram um padrão semelhante, desde a recepção do caranguejo, passando pelo beneficiamento e armazenamento, até a distribuição final da carne de caranguejo. Diferenciando-se um do outro apenas por um grau de conhecimento ou costumes que acabam por culminar numa convergência de suas práticas quanto à manipulação.

Tabela 3. Estimativa de receita dos quebradores com a venda da carne de caranguejo em Parnaíba, PI. * Calculo estimado para peso médio de $188 \mathrm{~g}$ (Galvão et al., 2010), 21\% de rendimento de carne (Ogawa et al., 2008) e custo médio de $\mathrm{R} \$ 0,20$ /caranguejo.

\begin{tabular}{lcccc}
\hline $\begin{array}{l}\text { Produção } \\
\mathrm{kg} / \text { mês }\end{array}$ & $\begin{array}{c}\text { Preço de } \\
\text { venda/kg } \\
(\mathrm{R} \$)\end{array}$ & $\begin{array}{c}\text { Renda } \\
\text { familiar } \\
(\mathrm{R} \$)\end{array}$ & $\begin{array}{c}\text { Custo da } \\
\text { matéria- } \\
\text { prima, } \text { R }^{*}\end{array}$ & $\begin{array}{c}\text { Renda } \\
\text { mensal, } \\
\mathrm{R} \$\end{array}$ \\
\hline 35,0 & 25,00 & 875,00 & 260,00 & 605,00 \\
67,5 & 25,00 & 1687,5 & 260,00 & 1427,5 \\
100,0 & 25,00 & 2500,00 & 260,00 & 2240,00 \\
\hline
\end{tabular}

Condições e práticas de beneficiamento, acondicionamento e comercialização da carne de caranguejo processada artesanalmente

O caranguejo é recepcionado no quintal ou área externa, sendo desamarrado e cozido imediatamente. Alguns locais realizam a sangria com o auxílio de uma ferramenta pontiaguda. $\mathrm{O}$ cozimento é realizado em tachos grandes em fogão a lenha, para economia de gás. Após o cozimento, os caranguejos são colocados em isopores e são levados em porções aos quebradores.

A seguir, inicia-se a etapa de extração propriamente dita da carne. A infraestrutura disponível é constituída por mesas e apetrechos de madeira. O resíduo (exoesqueletos) é jogado ao chão, embaixo das mesas (Figura 2A). O local de manipulação é aberto, possuindo uma cobertura adaptada. Há presença de insetos e animais de estimação.

Os quebradores não usam uniformes ou aventais e manipulam o produto com as mãos, sem o uso de luvas (Figura 2B). A carne extraída é colocada em bacias, que quando cheias, são levadas à cozinha para pesagem, embalagem e congelamento. As balanças são convencionais e muitas vezes antigas e enferrujadas. Sacos plásticos descartáveis com capacidade para $1,0 \mathrm{~kg}$ são usados para embalar a carne. $\mathrm{O}$ congelamento é realizado em freezer caseiro (Figura 2C).

O processo utilizado pelos quebradores é semelhante ao observado em outros centros consumidores de caranguejo (Cavalcante et al., 2011) e segue a linha de beneficiamento usada em indústrias processadoras de caranguejo (Dima et al., 2016). No entanto, por se tratar de uma atividade artesanal tradicional, há utilização de locais adaptados e materiais em madeira o que limita a capacidade de limpeza e higienização dos 
apetrechos e dos manipuladores. Segundo Vieira

fonte de contaminação. et al. (2004) esse tipo de processamento pode ser
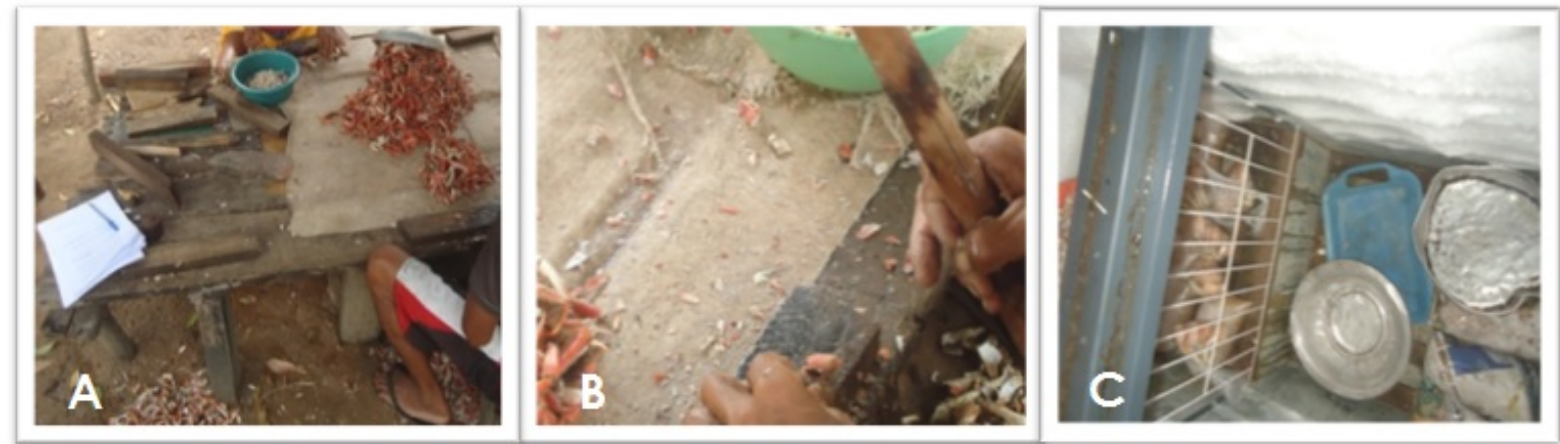

Figura 2. Práticas na extração de carne de caranguejo uçá observadas em Parnaíba, PI. (A) Caranguejos cozidos e carne extraída (bacia) dispostos em uma mesa de madeira adaptada no quintal, com resíduos ao chão. (B) Detalhe da quebra do caranguejo. (C) Armazenamento em freezer caseiro, sem higienização e com outros alimentos no mesmo local.

O congelamento em freezer doméstico também representa um problema para qualidade da carne de caranguejo. Isso porque a temperatura ao longo do armazenamento doméstico pode chegar a $-5^{\circ}$ C (Tsironi et al., 2009) quando a média recomendada é de $-18^{\circ}$ C. Além disso, o congelamento caseiro é lento (em torno de 8 a 12 horas), enquanto o industrial é rápido ( 2 a 3 horas). Fatores como o congelamento e armazenamento da carne afetam a sua estrutura, composição e funcionalidade, influenciando na sua vida de prateleira (Careche et al., 2015).

Conhecimentos sobre contaminação de alimentos, Doenças transmitidas pelos alimentos e boas práticas de manipulação

As condições higiênico-sanitárias precárias e a falta de boas práticas no beneficiamento do caranguejo estão diretamente vinculadas à baixa de escolaridade dos quebradores, ao baixo retorno financeiro da atividade e à ausência de treinamento na área de manipulação de alimentos. Observou-se que $62,5 \%$ dos entrevistados não sabiam dizer o que eram boas práticas na manipulação de alimentos (BPMA); 12,5\% disseram tomar cuidados com a queda de cabelos e objetos e a lavagem dos utensílios; 12,5\% relacionaram as BPMA com a higiene da cozinha e mãos; e os restantes $12,5 \%$ disseram que a qualidade da carne depende da limpeza e cuidado na extração e embalagem. Todos esses aspectos citados estavam corretos. As falhas de higiene pessoal, ambiental ou nos cuidados com os alimentos, podem contaminar os alimentos através das mãos, do cabelo e do acondicionamento dos produtos (Sultana et al., 2013).
Ao serem entrevistados, $75 \%$ disseram que conheciam o termo "contaminação de alimentos". No entanto, quando solicitados a especificarem como ocorria a contaminação, $12,0 \%$ disseram não saber; $12,0 \%$ disseram ocorrer na praia; $13,0 \%$ que a contaminação acontecia ao comer caranguejo morto; $25,0 \%$ que estava relacionada à má conservação e manipulação do caranguejo; e a maioria $(38,0 \%)$ relacionou a contaminação à exposição do produto sem refrigeração (igura 3).

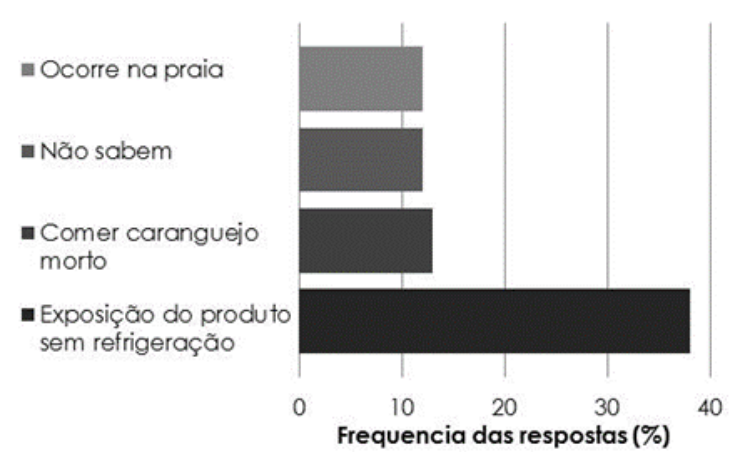

Figura 3. Conhecimento dos quebradores de carne de caranguejo em Parnaíba, PI, sobre a ocorrência da contaminação de alimentos.

Ainda dentro do contexto sobre a contaminação dos alimentos, os quebradores foram entrevistados com relação aos lugares onde esta poderia acontecer dentro dos restaurantes e cozinhas. Cerca de $25,0 \%$ não souberam dizer e outros $25,0 \%$ disseram não utilizar cozinhas. As demais respostas foram equilibradas: $12,5 \%$ responderam que poderia ocorrer com a falta de higiene; $12,5 \%$ em todos os locais; $12,5 \%$ próximo a lixeira e $12,5 \%$ pelas mãos. É interessante notar que apesar de não terem tido treinamentos na área de higiene e manipulação, as respostas estavam relacionadas aos principais 
fatores que contaminam os alimentos. No entanto, não havia exercício prático desses conhecimentos no dia a dia, porém esses dados mostram o conhecimento adquirido com a experiência do trabalho diário (Scott and Vanick, 2007).

Os manipuladores também foram questionados com relação às doenças causadas por alimentos. A maioria $(37,0 \%)$ citou a infecção intestinal como a principal e $25,0 \%$ não souberam citar nenhuma doença conhecida (Figura 4).

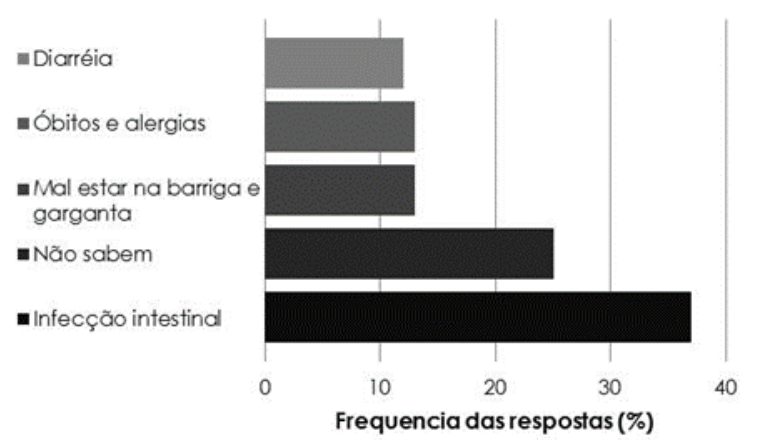

Figura 4. Conhecimento dos quebradores de carne de caranguejo em Parnaíba, PI, sobre as doenças causadas pela contaminação dos alimentos.

A totalidade dos entrevistados (100\%) citou ser importante a boa higiene pessoal para trabalhar com alimentos. Um dos itens básicos para manipulação de alimentos é a boa higiene das mãos que desempenha importante papel evitando a propagação de doenças infecciosas (Afifi and Abushelaibi, 2012). Essa prática foi citada por apenas $37,5 \%$ dos entrevistados, que também listaram o uso de luvas, toucas, aventais e o próprio asseio pessoal como ações necessárias para um manipulador de alimento (Figura 5).

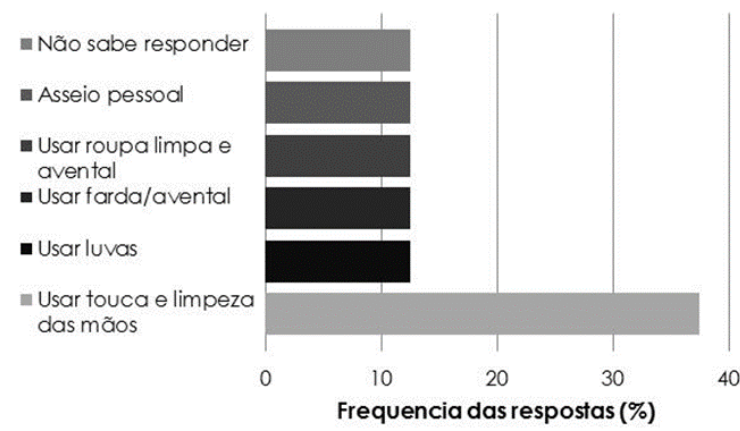

Figura 5. Conhecimento dos quebradores de carne de caranguejo em Parnaíba, PI, sobre aspectos importantes na higiene pessoal.

A higiene pessoal e o uso de vestuários que evitem a contaminação dos alimentos fazem parte das Boas Práticas de Fabricação (BPF), que são medidas obrigatórias a fim de garantir a conformidade dos produtos alimentícios segundo a legislação brasileira (Devides et al., 2014). No caso dos quebradores de Parnaíba, não há essa orientação por parte dos serviços de vigilância sanitária e por tratar-se de um processo tradicional, é preciso a criação de normativas específicas para essa atividade, semelhante à criação da Lei de transporte do caranguejo-uçá (Instrução Normativa 09/2013 do Ministério da Pesca e Aquicultura).

Qualidade microbiológica da carne de caranguejo uçá

A qualidade microbiológica do alimento está diretamente relacionada à condição higiênica em que ele foi processado. As doenças transmitidas por alimentos (DTA's) estão vinculadas à presença de Staphylococcus aureus e de Salmonella sp., dentre outros agentes infecciosos. Os estafilococos estão presentes na nasofaringe humana (Xavier et al., 2007) e possui alta virulência, resistência aos antimicrobianos, sendo associados a várias doenças infecciosas e intoxicações alimentares (Beraldo-Massoli et al., 2014).

As salmonelas são consideradas as principais bactérias causadoras de DTA's no mundo e estudos desenvolvidos no Brasil (Welker et al., 2010) relataram sérios riscos à saúde, podendo levar o doente a óbito nos casos mais graves (WHO, 2010).

Apesar das precárias condições observadas, por se tratar de um produto cozido a $90{ }^{\circ} \mathrm{C}$, os parâmetros microbiológicos estavam satisfatórios para todas as amostras coletadas em Parnaíba, PI (Tabela 4). Ogawa et al. (2008) observaram contagens microbiológicas semelhantes para carne de caranguejo após processo de pasteurização a 85 ${ }^{\circ} \mathrm{C}$ realizado em laboratório.

Tabela 4. Características microbiológicas da carne de caranguejo-uçá processada artesanalmente em Parnaíba, PI. $\mathrm{UFC}=$ Unidades formadoras de colônias.

\begin{tabular}{lccc}
\hline \multicolumn{3}{c}{$\begin{array}{c}\text { Estafilococos } \\
\text { QuebradorSalmonella } \text { sp. coagulase positiva, } \\
\text { UFC g }\end{array}$} & $\begin{array}{c}\text { Coliformes a } \\
45^{\circ} \mathrm{C}, \mathrm{UFC} \mathrm{g}^{-1}\end{array}$ \\
\hline $\mathrm{A}$ & Ausência & $<1,0 \times 10$ & $<1,0 \times 10$ \\
$\mathrm{~B}$ & Ausência & $<1,0 \times 10$ & $<1,0 \times 10$ \\
$\mathrm{C}$ & Ausência & $<1,0 \times 10$ & $1,0 \times 10^{2}$ \\
$\mathrm{D}$ & Ausência & $<1,0 \times 10$ & $<1,0 \times 10$ \\
$\mathrm{E}$ & Ausência & $<1,0 \times 10$ & $<1,0 \times 10$ \\
$\mathrm{~F}$ & Ausência & $<1,0 \times 10$ & $<1,0 \times 10$ \\
$\mathrm{G}$ & Ausência & $<1,0 \times 10$ & $3,0 \times 10$ \\
$\mathrm{H}$ & Ausência & $<1,0 \times 10$ & $<1,0 \times 10$ \\
\hline
\end{tabular}




\section{Conclusões}

A prática no beneficiamento e comercialização da carne de caranguejo ainda está pautada em costumes passados de pai para filho, em sistema familiar, admitindo-se vícios na manipulação desse alimento. A baixa profissionalização dos manipuladores está relacionada ao baixo rendimento financeiro da atividade com consequente falta de capacitações em Boas Práticas de Manipulação de Alimentos.

Apesar dessas condições citadas, a qualidade microbiológica da carne de caranguejo processada artesanalmente apresenta parâmetros sanitários satisfatórios.

Há necessidade de ações estruturantes e educacionais no sentido de proporcionar à Parnaíba as condições necessárias no campo gastronômico e turístico, diretamente relacionadas à saúde coletiva. Com um programa de controle higiênico-sanitário ordenado, será garantida a produção de alimento seguro, como também serão promovidos mecanismos de propagação do conhecimento sobre segurança de alimentos e boas práticas de produção, contribuindo para o estabelecimento de um estilo de vida comportamental focado na qualidade dos alimentos.

Há de se investir em uma socioeconomia comprometida com o meio ambiente; com a dignidade humana através da regularização do comércio caranguejeiro, do fomento ao conhecimento e a autoestima dos quebradores; mas principalmente com a geração de renda e o desenvolvimento social.

\section{Referências Bibliográficas}

Afifi, H. S. \& Abushelaibi, A. A. 2012. Assessment of personal hygiene knowledge, and practices in Al Ain, United Arab Emirates. Food Control, 25, 249-253.

Agência Nacional Reguladora. 2014. Vigilância Epidemiológica das Doenças Transmitidas por Alimentos - VE-DTA Agencia Nacional de Restaurantes. www.anrbrasil.org.br

Andrade, G. R. B., Vaitsman, J. \& Farias, L. O. 2010. Metodologia de elaboração do Índice de Responsividade do Serviço (IRS). Caderno de Saúde Pública, 1, 523-534.

ANVISA. 2001. Resolução - RDC n.12, de 02 de janeiro de 2001. In: Regulamento Técnico Sobre Padrões de Qualidade para Alimentos. Diário Oficial da União, Brasília, DF, Brasil.
Banco Mundial. 2008. Dollar a day revisited. Working Paper 4620. Disponível em $<$ http://dx.doi.org/10.1596/1813-9450-4620> Acesso em 01/01/2016.

Beraldo-Massoli, M. C., Cardoso, M. V., Cavani, R., Gomes, M. d. O. S. \& Schocken-Iturrino, R. P. 2014. Qualidade microbiológica de frango comercializado na cidade de Jaboticabal, São Paulo. Investigação, 13, 2428.

Borcem, E. R., Júnior, I. F., Almeida, I. C., Silva Palheta, M. K. \& Pinto, I. A. 2012. A atividade pesqueira no município de Marapanim-Pará, Brasil. Amazonian Journal of Agricultural and Environmental Sciences, 54, 189-201.

Brabo, M. F. 2009. Adequações tecnológicas no beneficiamento do caranguejo-uçá Ucides cordatus (Linnaeus, 1763) desenvolvido na comunidade de Caratateua, município de Bragança, estado do Pará, Brasil. Universidade Federal do Pará, Belém, Paraá.

Calvet, R. M., Lima, M. F. V., Lacerda, L. M., Lima, B. G., Silva, M. I. S. \& Muratori, M. C. S. 2010. Avaliação higiênico-sanitária de sushis servidos em restaurantes orientais na cidade de São Luís, MA. Higiene Alimentar, 24, 108-112.

Careche, M., Carmona, P. \& Sánchez-Alonso, I. 2015. Monitoring the time and temperature history of frozen hake (Merluccius merluccius, L.) muscle by FTIR spectroscopy of the lipid fraction. Food and Bioprocess Technology, 8, 112-119.

Cavalcante, A. N., Almeida, Z. S., Paz, A. C. \& Nahum, V. J. I. 2011. Análise multidimensional do sistema de produção pesqueira Caranguejo-Uçá, ucides cordatus, no município de Araioses, Maranhão-Brasil. Arquivos de Ciências do Mar, 44, 87-98.

Comissão Ilha Ativa. 2015. Saberes para proteção do extrativismo da Ilha Grande de Santa Isabel. SIEART, Parnaíba, PI, Brasil. 48 p.

Devides, G. G. G., Maffei, D. F. \& Catanozi, M. P. L. M. 2014. Perfil socioeconômico e profissional de manipuladores de alimentos e o impacto positivo de um curso de capacitação em boas práticas de fabricação. Brazilian Journal of Food Technology, 17, 166-176.

Dima, J. B., Baron, P. \& Zaritzky, N. 2016. Pasteurization conditions and evaluation of quality parameters of frozen packaged crab meat. Journal of Aquatic Food Product Technology, 25, 745-759. 
Freitas, S. T., Pamplin, P. A. Z., Legat, J., Fogaça, F. H. S. \& Barros, R. F. M. 2012. Conhecimento tradicional das marisqueiras de Barra Grande, área de proteção ambiental do delta do Rio Parnaíba, Piauí, Brasil. Ambiente \& Sociedade, 15, 91-112.

Galvão, S. S. H., Marinho, R. A. \& Conceição, L. R. N. 2010. El consumo de cangrejo ucides cordatus (linnaeus, 1763) en Fortaleza, Ceará, Brasil. Boletim Técnico e Científico do Cepnor, 10, 9-19.

Instituto Brasileiro de Geografia e Estatística. 2015. Censo 2015. Disponível em< http://www.ibge.gov.br/home/estatistica/popul acao/censo2015/default.shtm> Acesso em 20/12/2015.

Lakatos, E. M. \& Marconi, M. A. 2010. Fundamentos da metodologia científica. Fundamentos da metodologia científica. Altas, São Paulo, Brasil.

Nishida, A. K., Nordi, N. \& Alves, R. R. d. N. 2008. Aspectos socioeconômicos dos catadores de moluscos do litoral paraibano, Nordeste do Brasil. Revista de Biologia e Ciências da Terra, 8, 207-215.

Ogawa, M., Silva, A. I. M., Ogawa, N. B. P., Maia, E. L. \& Nunes, M. L. 2008. Adequações tecnológicas no processamento da carne de caranguejo. Sociedade Brasileira de Ciência e Tecnologia de Alimentos, 28, 78-82.

Ristori, C. A., Iaria, S. T., Gelli, D. S. \& Rivera, I. N. G. 2007. Pathogenic bacteria associated with oysters (Crassostrea brasiliana) and estuarine water along the south coast of Brazil. International Journal of Environmental Health Research, 17, 259-269.

Saint-Paul, U. \& Schneider, H. 2016. The need for a holistic approach in mangrove-related fisheries research: a specific review of the German and Brazilian research project MADAM. Journal of Fish Biology, 89, 601618.

Sarnoski, P. J., O’Keefe, S. F., Jahncke, M. L., Mallikarjunan, P. \& Flick, G. J. 2010. Analysis of crab meat volatiles as possible spoilage indicators for blue crab (Callinectes sapidus) meat by gas chromatography-mass spectrometry. Food Chemistry, 122, 930-935.

Scott, E. \& Vanick, K. 2007. A survey of hand hygiene practices on a residential college campus. American Journal of Infection Control, 35, 694-696.
Sousa, D. B., Santos, N. B., Oliveira, V. M., Carvalho-Neta, R. N. F. \& Almeida, Z. S. 2015. Carcinofauna bêntica estuarina de dois manguezais da costa amazônica maranhense, Brasil. Iheringia. Série Zoologia, 105, 339347.

Sultana, A., Awan, A. \& Tehseen, I. 2013. Sanitation practices among food handlers working in street restaurants in Rawalpindi, Pakistan. Rawal Medical Journal, 38, 425-427.

Tsironi, T., Dermesonlouoglou, E., Giannakourou, M. \& Taoukis, P. 2009. Shelf life modelling of frozen shrimp at variable temperature conditions. LWT-Food Science and Technology, 42, 664-671.

Vieira, R. H. S. F., Rodrigues, D. d. P., Barreto, N. S. E., Sousa, O. V., Tôrres, R. C. O., Ribeiro, R. V., Saker-Sampaio, S., Nascimento, S. M. M., Costa, F. d. A. P. d. \& Madeira, Z. R. 2004. Microbiologia, higiene e qualidade do pescado: teoria e prática. Varela, São Paulo, Brasil.

Welker, C. A. D., Both, J. M. C., Longaray, S. M., Haas, S., Soeiro, M. L. T. \& Ramos, R. C. 2010. Análise microbiológica dos alimentos envolvidos em surtos de doenças transmitidas por alimentos (DTA) ocorridos no estado do Rio Grande do Sul, Brasil. Revista Brasileira de Biociências, 8, 44-48.

WHO. 2010. World Health Organization. Strategies to monitor and evaluate population sodium consumption and sources of sodium in the diet. In: Canada, R. o. a. J. T. M. C. b. W. a. t. G. o. (ed.) WHO technical report series. Canada.

Xavier, C. A. C., Oporto, C. F. O., Silva, M. P., Silveira, I. A. \& Abrantes, M. R. 2007. Prevalência de Staphylococcus aureus em manipuladores de alimentos das creches municipais da cidade do Natal/RN. Revista Brasileira de Análises Clínicas, 39, 165-168.

\section{Article History:}

Received 24 February 2017

Accepted 24 April 2017

Available on line 18 May 2017

License information: This is an open-access article distributed under the terms of the Creative Commons Attribution License 4.0, which permits unrestricted use, distribution, and reproduction in any medium, provided the original work is properly cite. 